\title{
Prevalence of musculoskeletal disorders among farmers
}

\begin{abstract}
Musculoskeletal disorders (MSDs) can affect the body's muscles, joints, tendons, ligaments and nerves. Most work-related MSDs develop over time and are caused either by the work itself or by the employees' working environment. A cross sectional study was conducted among conveniently selected 200 farmers to assess prevalence of musculoskeletal problems. This study was conducted in Sengua, Sharishabari of Jamalpur district in Bangladesh. A structured pretested questionnaire was used to collect data. Face to face interview as well as physical examination was done by physiotherapist. Mean age was $30.83 \pm$ (SD 6.064). Mean working years was $14.58 \pm$ (SD 6.385). Among the 200 participants $78 \%$ had musculoskeletal disorders. Significant association was found between musculoskeletal disorders and age, working years, working day and working time $(\mathrm{p}<0.05)$. Low back pain was very common. More than three forth of the respondents had musculoskeletal problem.
\end{abstract}

Keywords: Musculoskeletal disorders, Farmers
Volume 4 Issue I - 2016

\author{
Altaf Hossain Sarker, ${ }^{2}$ Mohammad Shariful \\ Islam,' Md Monoarul Haque, ${ }^{3}$ Tarafder Nahid \\ Parveen ${ }^{2}$ \\ 'Department of Physiotherapy, The Peoples University of \\ Bangladesh, Bangladesh \\ ${ }^{2}$ bon Sina D Lab, Dhaka \\ ${ }^{3}$ Bangladesh Physiotherapy Association, Bangladesh \\ Correspondence: M Md Monoarul Haque, Bangladesh \\ Physiotherapy Association, 125/I, Darus Salam, Mirpur, \\ Dhaka-1216, Bangladesh, Tel 88 01915839550, \\ Email monoarmunna@yahoo.com
}

Received: December 10,2015 | Published: January 07, 2016

\section{Introduction}

Farming is an occupation that predisposes individual to health problems including musculoskeletal disorders (MSDs). ${ }^{1}$ Farming is a hazardous activity ${ }^{2}$ which presents a range of threats to health. ${ }^{3}$ MSDs affect millions of people around the world and are the most common cause of severe long-term pain and physical disability. In addition to their physical effects, MSDs affect the psychosocial status of individual and impact on their families and careers. ${ }^{4} \mathrm{~A}$ survey of 15 European countries showed that agriculture is one of the industries with the most exposure to heavy physical loads. ${ }^{5} \mathrm{~A}$ number of national and international studies have shown that farming is a physically demanding occupation with work tasks that can cause musculoskeletal disorders (MSD). ${ }^{1}$ A Swedish study found that the odds of reporting musculoskeletal problems were $51 \%$ higher among farmers than non-farmers. ${ }^{6}$ Farming is a physically demanding occupation with work tasks that cause MSDs and work disability such as lifting heavy objects, moving and carrying equipment and awkward working postures. ${ }^{7}$ Many type of work cause pain and discomfort when farmers are not aware of ergonomic consideration of their work task. Muscle soreness and other discomfort with injuries sometimes also associated with using tools of agriculture, which can actually occur from performing any number of activities. Infect misuse of the same muscles during multiple activities can create a problem. A lot of studies were done in abroad regarding this topic to determine the prevalence of musculoskeletal disorder but very few study were conducted on this regard in our country. Among the few studies that were found locally not sufficient to present the real picture of the situation due to shortage of information and studies were conducted couple of year back which does not represent the present situations on this regard, so it is very much urgent to know the situation.

\section{Methodology}

\section{Study design: Cross sectional}

Study setting: This study was conducted in Sengua, Sharishabari of Jamalpur district in Bangladesh.

Study population: Farmers whose age between 18 to 40 years was included in this study. Many farmers were affected in musculoskeletal disorders (MSDs).

Study duration: The duration of the study was six months from September 2014 to March 2015.

Population size: Total of 384 subjects was included for the study by using convenient sampling method.

\section{Criteria for selection}

\section{Inclusion criteria}

I. Those who gave consent and participated for interview.

II. Only male farmer age between 18-40 years.

III. Duration of working years was minimum 2years.

\section{Exclusion criteria}

\section{Refusal to give informed consent}

II. Age below 18 or above 40 years

Data collection instrument/tools: An interviewer administered structured questionnaire was designed to collect information on related musculoskeletal disorders(MSDs) among farmers, that was prepared in advance and evaluated by the principal supervisor before data collection.

Data collection procedure: Data collection was performed by face to face interview.

Data management and analysis: After collection of data, all interview questionnaires were checked for its completeness correctness and internal consistency to exclude missing or inconsistent data. Corrected data was entered into the computer. The data were analyzed by using the statistical software namely SPSS [Statistical Package for Social Sciences].

\section{Results}

Mean age was $30.83 \pm($ SD 6.064). Distribution of age was 18-27 years: $39 \%$; $28-37$ years: $55 \%$; $38-40$ years: $6 \%$ (Table 1 ). 
Among the respondent mean working years was $14.58 \pm(\mathrm{SD} 6.385)$ Distribution of working year was 2-11years: $32.5 \%$; 12-21years: $50 \%$; 22-26years: $17.5 \%$. Among the all participants $2.5 \%$ worked once a week, $6.5 \%$ worked $2-3$ days in a week and $91.0 \%$ worked 4 days per week. About $5.5 \%$ participants worked less than 8 hours in a day, $6.5 \%$ worked $8-10$ hours in a day, $69.0 \%$ worked $11-12$ hours and $19.0 \%$ worked more than 12 hours (Table 2 ).

Among the 200 participants $22 \%$ had no musculoskeletal disorders and $78 \%$ had musculoskeletal disorders (Figure 1).

More than half of the respondents suffered from low back pain followed by upper back pain (18.5\%), shoulder pain (20\%) and foot pain $(5.5 \%)$ (Table 3$)$.

Significant association was found between musculoskeletal disorders and age, working years, working day and working time $(\mathrm{p}<0.05)$ (Table 4).

Table I Age group of the respondents

\begin{tabular}{lll}
\hline Age Group & Number & Percentage \\
\hline $18-27$ & 78 & 39 \\
$28-37$ & 110 & 55 \\
$38-40$ & 12 & 6 \\
Total & 200 & 100 \\
Mean & $30.83 \pm 6.06$ & \\
\hline
\end{tabular}

Table 2 Work related characteristics of the respondents

\begin{tabular}{lll}
\hline Working Years & Number & Percentage \\
\hline II-Feb & 65 & 32.5 \\
21 -Dec & 100 & 50 \\
$22-26$ & 35 & 17.5 \\
Working Day/Week & & \\
I & 0 & 0 \\
2 & 5 & 2.5 \\
3 & 13 & 6.5 \\
4 & 182 & 91 \\
Working Hour/Day & & \\
$<8$ & 11 & 5.5 \\
$8-10$ & 13 & 6.5 \\
II-12 & 138 & 69 \\
$>12$ & 38 & 19 \\
Total & 200 & 100
\end{tabular}

Table 3 Distribution of risk factor of musculoskeletal disorders among respondents

\begin{tabular}{lll}
\hline +Musculoskeletal Disorders & Number & Percentage \\
\hline Neck Pain & II & 5.5 \\
Shoulder Pain & 40 & 20 \\
Arm Pain & 10 & 5 \\
Elbow Pain & 6 & 3 \\
Forearm Pain & 4 & 2 \\
Wrist Pain & 9 & 4.5 \\
Finger Pain & 9 & 4.5 \\
Upper Back Pain & 37 & 18.5 \\
Lower Back Pain & 101 & 50.5 \\
Hip Pain & 18 & 9 \\
Knee Pain & 9 & 4.5 \\
Leg Pain & 10 & 5 \\
Ankle Pain & 7 & 3.5 \\
Foot Pain & 11 & 5.5
\end{tabular}

Table 4 Association between musculoskeletal disorders and variables of interest

\begin{tabular}{|c|c|c|c|c|}
\hline \multirow{2}{*}{ Variables } & \multicolumn{3}{|c|}{ Musculoskeletal Disorders } & \multirow{2}{*}{ p-value } \\
\hline & Yes $(n=156)$ & No $(n=44)$ & $\chi^{2}$ & \\
\hline \multicolumn{5}{|l|}{ Age } \\
\hline 18-27years & 44 & 34 & \multirow{2}{*}{35.254} & \multirow{2}{*}{0.001} \\
\hline 38-40years & 12 & 0 & & \\
\hline \multicolumn{5}{|c|}{ Working Years } \\
\hline II-Feb & 31 & 33 & \multirow{3}{*}{67.144} & \multirow{3}{*}{0.001} \\
\hline 2I-Dec & 90 & 10 & & \\
\hline $22-26$ & 36 & I & & \\
\hline \multicolumn{5}{|c|}{ Working Day in a Week } \\
\hline I & 3 & 2 & \multirow{3}{*}{19.431} & \multirow{3}{*}{0.001} \\
\hline 3-Feb & 4 & 9 & & \\
\hline 4 & 149 & 33 & & \\
\hline \multicolumn{5}{|c|}{ Working Hour in a Day } \\
\hline$<8$ & 7 & 4 & \multirow{4}{*}{20.018} & \multirow{4}{*}{0.001} \\
\hline 10-Aug & 6 & 7 & & \\
\hline 12-Nov & 105 & 33 & & \\
\hline$>12$ & 38 & 0 & & \\
\hline
\end{tabular}

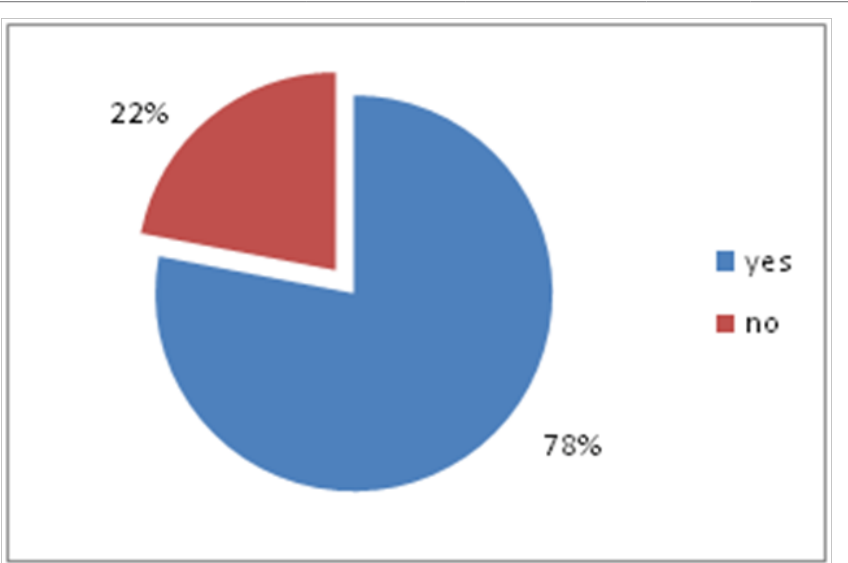

Figure I Distribution of musculoskeletal disorders among of the respondents.

\section{Discussion}

Musculoskeletal disorders (MSDs) refer to conditions that involve the nerves, tendons, muscles, and supporting structures of the body. The risk factors for MSDs include awkward posture, repetition, force, vibration, velocity of work, tool design, and personal factors. Musculoskeletal symptoms (MSS) include pain, sensitivity, weakness, swelling, and numbness. ${ }^{8}$ In this study $78 \%$ farmers had MSDs and $22 \%$ had no MSDs. Among the 200 participants More than half of the respondents suffered from low back pain followed by upper back pain $(18.5 \%)$, shoulder pain $(20 \%)$ and foot pain $(5.5 \%)$. Statistical significant association was found between musculoskeletal disorders and age, working years and musculoskeletal disorders, working day and musculoskeletal disorders and working time and musculoskeletal disorders $(p<0.05)$. Dairy farming is physically demanding and associated with a high frequency of musculoskeletal disorders (MSD). This study investigated and compared work-related MSD, ergonomic work factors and physical exertion in farmers and employed farm workers on dairy farms in Sweden. ${ }^{9}$ In a survey of Southeast Kansas farmers ${ }^{10}$ nearly $60 \%$ of the respondents reported that they experienced a farm work-related MSD symptom during the last 12 months, while a survey of self-reported work-related illness in Britain during 1995 found that 43000 or $7 \%$ of the agriculture workforce ascribed MSDs to their work. ${ }^{11}$ 
According to the Swedish Work Environment Authority, 70\% of reported occupational diseases among people engaged in Swedish farming relate to the musculoskeletal system, compared with 55\% for all other occupations. ${ }^{12}$ In the European Union, MSD are the most commonly reported work-related health problems, with $23 \%$ of European workers reporting that they suffer from aches and pains in the musculoskeletal system. ${ }^{13}$ In a number of studies, male farmers reported significantly more musculoskeletal symptoms than other occupationally active men in Sweden, ${ }^{6}$ Finland ${ }^{14}$ and other countries. ${ }^{15}$ Recent reviews concluded that twisting, bending, manual material handling and exposure to whole-body vibrations were risk factors for low back pain. ${ }^{16}$ However, the impact of heavy physical work in general on low back problems is still inconclusive. Moreover, high physical workload has been proposed as a contributing factor in the development of osteoarthritis of the hip ${ }^{17}$ and the knee. ${ }^{18}$ Neck and shoulder symptoms have also been related to working conditions, especially monotonous and repetitive work tasks. ${ }^{19}$ In addition, psychosocial factors seem to have a large impact on neck and shoulder problems, as well as on low back pain. ${ }^{20}$ In a previous study, we found that farmers reported significantly more hand and forearm problems, low back pain and hip problems than non-farmers, and tended to shave more neck and shoulder and knee problems. ${ }^{6}$

\section{Conclusion}

This study concludes that most of the farmers suffer from lower back pain followed by shoulder pain. More than three forth of the respondents had musculoskeletal problem.

\section{Acknowledgments}

None.

\section{Conflicts of interest}

None.

\section{References}

1. Osborne A, Blake C, McNamara J, et al. Musculoskeletal Disorders Among Irish Farmers. Occupational Medicine. 2010;60(8):598-603.

2. Lewis MQ, Sprince NL, Burmeister LF, et al. Work-related injuries among Iowa farm operators. Am J Ind Med. 1998;33(5):510-517.

3. Essen VSG, McCurdy SA. Health and Safety Risks In Production agriculture. West J Med. 1998;169(4):214-220.

4. Woolf A, Pfleger B. Burden of major musculoskeletal conditions. Bulletin of the World Health Organization. 2003;81(9):646-656.

5. Paoli P, Merllie D. Third European Survey on Working Conditions 2000. European Foundation for the Improvement of Living and Working Conditions. 2001.
6. Holmberg S, Stiernström EL, Thelin A, et al. Musculoskeletal Symptoms Among Farmers And Non-Farmers: A Population-Based Study. Int J Occup Environ Health. 2002;8(4):339-345.

7. Pinzke S, Stal M, Hansson GA. Physical Workload On Upper Extremities In Various Operations During Machine Milking. Ann Agric Environ Med. 2001;8(1):63-70.

8. Park JH, Lim HS, Lee K. Work-Related Musculoskeletal Symptoms Among Dairy Farmers In Gyeonggi Province, Korea. J Prev Med Public Health. 2010;43(3):205-212.

9. Kolstrup CL. Work-Related Musculoskeletal Discomfort Of Dairy Farmers And Employed Workers. Occupational Medicine and Toxicology. 2012;7:23.

10. Rosecrance J, Rodgers G, Merlino L. Low Back Pain And Musculoskeletal Symptoms Among Kansas Farmers. Am J Med. 2006;49:547-556.

11. Jones JR, Hodgson JT, Clegg TA. Self-Reported Work-Related Illness and workplace injuries in 2008/09: Results from a Household Survey. HSE. 1998;1-14.

12. Swedish Work Environment Authority. Work-Related Disorders 2010 (In Swedish). Stockholm: Arbetsmiljöverket. 2010.

13. European Agency for Safety and Health at Work. Prevention of workrelated MSDs in Practice. 2007.

14. Manninen P. Risk Factors Of Musculoskeletal Disorders And Work Disability Among Finnish Farmers (Dissertation). The social insurance institution, Koupio, Finland. 1996.

15. Maetzel A, Mäkelä M, Hawker G, et al. Osteoarthritis Of The Hip And Knee And Mechanical Occupational Exposure - A Systematic Overview Of The Evidence. J Rheumatol. 1997;24(8):1599-1607.

16. Burdorf A, Sorock G. Positive And Negative Evidence Of Risk Factors For Back Disorders. Scand Journal Work Environtal Health. 1997;23(4):243-256.

17. Vingård E, Alfredsson L, Goldie I, et al. Occupation And Osteoarthrosis Of The Hip And Knee: A Register-Based Cohort Study. Int J Epidemiol. 1991;20:1025-1031.

18. Sandmark H, Hogstedt C, Vingård E. Primary Osteoarthrosis Of The Knee In Men And Women As A Result Of Lifelong Physical Load From Work. Scand J Work Environ Health. 2000;26(1):20-25.

19. Jonsson BG, Persson J, Kilbom Å. Disorders Of The Cervicobrachial Region Among Female Workers In Electronics Industry. International Journal Industrial Ergonomics. 1988;3:37-47.

20. Barnekow-Bergkvist M, Hedberg GE, et al. Determinants of SelfReported Neck-Shoulder and Low Back Symptoms in a General Population. Spine. 1998;23(2):235-243. 